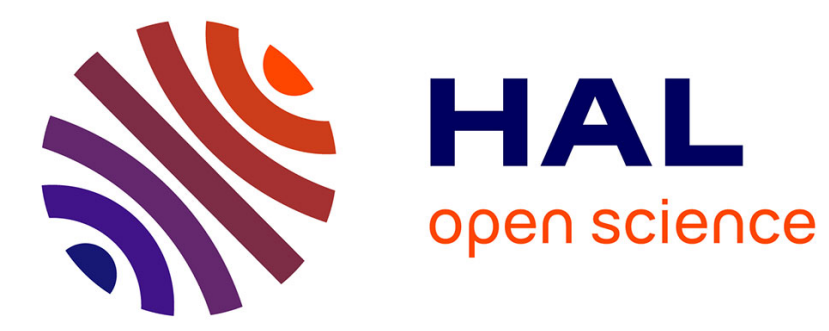

\title{
Coalescence of polymer droplets: experiments on collision
}

Claude Verdier

\section{To cite this version:}

Claude Verdier. Coalescence of polymer droplets: experiments on collision. Comptes Rendus de l'Academie des Sciences. Série IV, Physique, Astronomie, 1999, 1, pp.119-126. hal-00321757

\section{HAL Id: hal-00321757 \\ https://hal.science/hal-00321757}

Submitted on 16 Sep 2008

HAL is a multi-disciplinary open access archive for the deposit and dissemination of scientific research documents, whether they are published or not. The documents may come from teaching and research institutions in France or abroad, or from public or private research centers.
L'archive ouverte pluridisciplinaire HAL, est destinée au dépôt et à la diffusion de documents scientifiques de niveau recherche, publiés ou non, émanant des établissements d'enseignement et de recherche français ou étrangers, des laboratoires publics ou privés. 


\title{
Coalescence of polymer droplets: experiments on collision
}

\author{
Claude VERDIER \\ Laboratoire de Rhéologie \\ Universités de Grenoble (UJF-INPG) et CNRS (UMR 5520) \\ BP 53, Domaine Universitaire \\ 38041 Grenoble Cedex 9, France \\ Tel. 04-76-82-52-94 \\ Fax. 04-76-82-51-64 \\ E-mail: Claude.Verdier@ujf-grenoble.fr
}

\begin{abstract}
The coalescence of polymer droplets is a fundamental phenomenon which appears for example when mixing two polymers. When two polymeric droplets collide, a transient regime appears, which results from a competition between interfacial and viscoelastic effects : the spherical droplets deform to give birth to a new drop in a short time $\left(\mathrm{t}_{\mathrm{c}}\right)$ and the drop shape stabilizes after a long time.

A novel method is proposed to study experimentally under a microscope the collision between two droplets of one polymer in another one, with different viscosity ratios. This allows to determine the characteristic time $t_{c}$ which defines this phenomenon. The experiments actually show that $t_{c}$ varies like the geometric mean of the viscosities of the two polymers, for the case of a polydimethylsiloxane/polyisobutylene system.
\end{abstract}

\section{Coalescence de gouttelettes de polymères : expériences de collision}

Résumé - La coalescence de gouttelettes de polymères est un phénomène fondamental qui intervient par exemple lorsque l'on mélange deux polymères. Lorsque deux gouttelettes de polymères rentrent en collision, un régime transitoire apparaît, qui est régi par la compétition entre les effets de surface et les effets viscoélastiques : les gouttelettes sphériques se déforment pour donner naissance à une nouvelle goutte dans un temps rapide $\left(t_{c}\right)$ et la forme de cette goutte se stabilise dans un temps long.

Une nouvelle méthode est proposée pour étudier expérimentalement sous microscope la collision de deux gouttelettes d'un polymère dans un autre en faisant varier le rapport des viscosités. Ceci permet d'avoir accès au temps caractéristique $t_{c}$ qui définit le phénomène. Les expériences montrent que $t_{c}$ est en fait proportionnel à la moyenne géométrique des viscosités des deux polymères, dans le cas d'un système polydiméthylsiloxane/polyisobutylène.

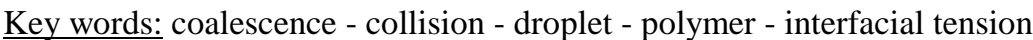

Mots-clés: coalescence - collision - gouttelette - polymère - tension interfaciale

Version française abrégée - Le terme de coalescence désigne en général le mécanisme global de rencontre de deux gouttes d'un milieu 1 placées dans un milieu 2. Ce processus peut être dû à des forces de natures différentes (mouvement Brownien, forces de van der Waals, forces extérieures comme un cisaillement, ...) et on peut le décomposer en plusieurs phases:

I. l'approche des gouttelettes avec le drainage du fluide interstitiel

II. l'ouverture d'un trou

III. la collision

La première étape a été bien décrite précédemment [1], en faisant plusieurs hypothèses concernant la nature de l'interface, mobile, partiellement mobile, ou fixe. La seconde étape est plus délicate mais

\footnotetext{
$\dagger$ Presented at the "Workshop on multicomponent and Multiphase Fluid Dynamics", Philadelphia, march 12-13, 1999.

* Dedicated to Professor Daniel D. Joseph, on the occasion of his 70th Birthday.
} 
suppose que lorsque l'écart entre les deux gouttelettes correspond à une distance caractéristique petite (de l'ordre de $50 \AA$ ̊ ), il se crée un trou permettant la réunion des deux gouttelettes.

C'est la troisième et dernière étape qui nous intéresse ici ; en outre elle a été peu étudiée dans la littérature. Il s'agit de comprendre les mécanismes qui régissent la déformation de la surface libre, à savoir l'influence couplée des effets de surface et viscoélastiques, afin de prédire quels sont les paramètres qui contrôlent réellement cette étape.

Pour cela, nous utilisons deux polymères fondus transparents, le polydimethylsiloxane (PDMS) et le polyisobutylene (PIB), en se plaçant sous un microscope. Sous l'action des seules forces de van der Waals, deux gouttelettes se rapprochent et se réunissent, ceci étant filmé à l'aide d'une caméra vidéo. Dans le système considéré, les effets élastiques sont négligeables.

Les résultats montrent qu'un première phase très rapide intervient, où la surface libre se déforme soumise à l'action prépondérante des forces de surface. Ensuite une deuxième étape plus longue se déroule (relaxation), pendant laquelle la goutte nouvellement formée atteint sa forme sphérique finale.

Le temps caractéristique $t_{c}$ de la première phase est mesuré en prenant l'inverse de la pente de la courbe $\mathrm{D}(\mathrm{t}) / \mathrm{D}_{0}$ en fonction du temps $\mathrm{t}\left(\mathrm{D}(\mathrm{t})\right.$ longueur totale de la nouvelle goutte, $\mathrm{D}_{0}$ longueur initiale) et il est porté sous forme adimensionnelle $\sigma \mathrm{t}_{\mathrm{c}} / \eta_{1} \mathrm{R}_{1}$ ( $\sigma$ est la tension interfaciale et $\mathrm{R}_{1}$ le rayon de la grosse gouttelette) en fonction du rapport des viscosités $\eta 1 / \eta 2$. La pente obtenue, pour différentes combinaisons de viscosités $\eta_{1}$ et $\eta_{2}$, est environ $-1 / 2$, ce qui veut dire que $t_{c}$ varie à peu près comme la moyenne géométrique des viscosités $\sqrt{\eta_{1} \eta_{2}}$.

\section{INTRODUCTION. -}

Coalescence usually describes the global mechanism by which two drops of a fluid 1 meet in a fluid 2 . This process may be due to different forces (Brownian forces, van der Waals ones, or exterior forces like shear, etc.) and can be divided into three different phases :

I. the approach of the droplets with the draining of the interstitial fluid

II. the opening of a hole

III. the collision

The first stage has been well described previously [1], several approaches consider mobile, partially mobile or immobile interfaces. The second stage is more delicate and requires a physical hypothesis assuming that a hole will appear when a certain small characteristic distance exists between the two droplets (typically $50 \AA$ ), then the droplets meet.

We consider here the final stage. In addition it has not been studied so much in the literature. Understanding the mechanisms of deformation of the free surface are essential, i.e. the competition between interfacial tension and viscoelasticity, in order to determine which are the relevant parameters governing this phenomenon.

In order to do so, we use two transparent polymer melts, a polydimethylsiloxane (PDMS) and polyisobutylene (PIB) and put this system under a microscope. Under the action of van der Waals forces only, two spherical droplets get closer and eventually meet, this being filmed using a video camera. In this particular system, elastic effects can be neglected.

Results show that a first rapid phase occurs, where the surface moves due to surface forces mainly. Then a second and longer phase is observed, during which the newly formed drop changes shape (relaxation) until it becomes spherical.

The characteristic time $t_{c}$ of the first stage is measured from the slope in the diagram $D(t) / D_{0}$ versus time $t\left(D(t)\right.$ total length of the new drop, $D_{0}$ initial length) and is plotted in its dimensionless form $\sigma t_{c} / \eta_{1} R_{1}(\sigma$ is the interfacial tension and $R_{1}$ the radius of the large droplet) against the viscosity ratio $\eta_{1} / \eta_{2}$. The slope obtained for various combinations of the viscosities $\eta_{1}$ and $\eta_{2}$ equals roughly $-1 / 2$, which means that $t_{c}$ varies roughly like the geometric mean of the two viscosities $\sqrt{\eta_{1} \eta_{2}}$.

\section{COLLISION OF SPHERICAL DROPS . -}

\section{Literature}

Coalescence and therefore collision are very important for they appear in various mixing problems (emulsions, blends) or in metallurgy (sintering of metallic powders [2]). They are also essential in colloids, coatings, foams and may be also relevant to cellular systems, in particular when discussing 
coagulation or aggregation. The resulting microstructure of the system or material greatly depends on coalescence phenomena.

Coalescence and break-up [3-9] are actually often associated in these systems because they appear at the same time and it may be difficult to predict which one is the governing mechanism. Droplets in elongation and shear situations have already been considered [6-7]. The most complete work on drainage in a coalescence process is due to Chesters [1] where a systematic analysis of the flow of the interstitial fluid is analyzed analytically using different interfaces, fixed, mobile or partially mobile. Numerical work has also been proposed [10] showing the onset of flattening before opening of a hole.

When thinking about a two-drop system, Frenkel's solution [11] may be recalled as well as experiments by Kuczynski [2], both showing the evolution of the radius of the hole which is opening like $t^{1 / 2}$ ( $t$ is time). More recently a close solution [12-13] was obtained for two-dimensional cases using mapping functions. The neck growth problem [14] was again treated experimentally in a complete manner for a polymeric system, showing correlation of the neck radius with the compliance over several decades in time. On the other hand, a very recent study [15] has proved that the initial evolution of the hole radius is like $\mathrm{t}^{1 / 7}$. But this study does not tell us how interfacial tension comes into this relation. In the same work, multiple air traps were computed numerically, which seems rather surprising.

Polymeric systems are also of interest. Models describing groups of droplets (blends) require a few statistical assumptions, in particular the number of droplets per unit volume and the probability for the drops to meet. Such models for coalescence [16-17] are based on the assumption that coalescence is possible only if draining of the interstitial fluid is fast enough. The study of copolymers has also been considered [18], showing their stabilizing effects, thus preventing coalescence. Models can finally predict the final diameter or its evolution in time [19-20]. It can be concluded that coalescence is more important than break-up in certain cases [21-23].

Nevertheless, the understanding of the coalescence process during collision is still not well understood, due to the strong nonlinearities involved (surface deformations, curvatures), therefore a careful experimental study is needed to understand this process and the governing parameters, and this is the aim of this work.

\section{Governing parameters}

Let us consider a system composed of two droplets of fluid 1 with viscosity $\eta_{1}$ and density $\rho_{1}$ in an outer fluid 2 of viscosity $\eta_{2}$ and density $\rho_{2}$ (figure 1 ). They have radii $R_{1}$ and $R_{2}$ and $\sigma$ is the interfacial tension.

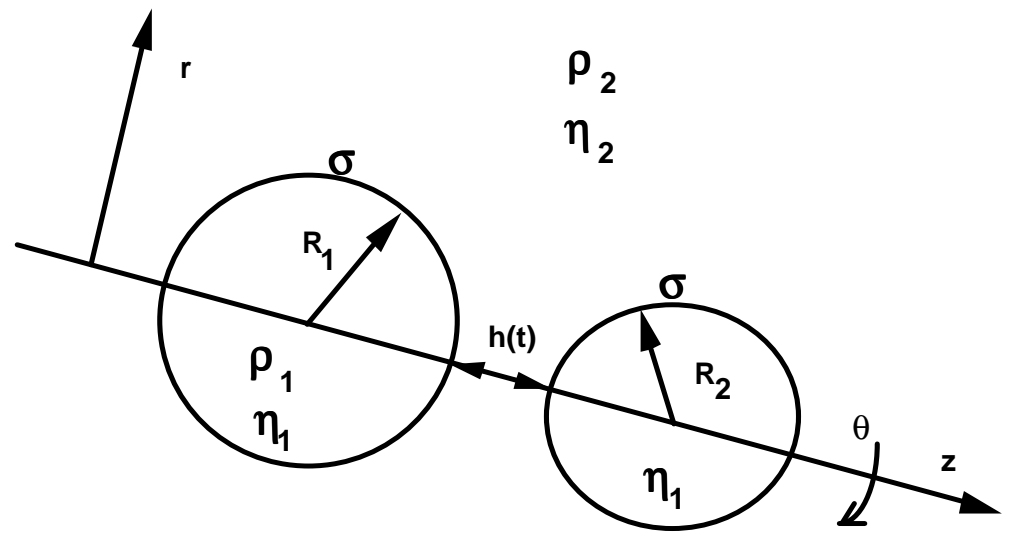

Fig. 1. - Sketch of the system

Fig. 1. - Schéma du système

The five dimensionless parameters are the radius ratio $R_{1} / R_{2}$, the viscosity ratio $\eta_{1} / \eta_{2}$, the density ratio $\rho_{1} / \rho_{2}$, a capillary number, say $\eta_{1} R_{1} / \sigma t_{c}$ (where $t_{c}$ is the characteristic time of the phenomenon, therefore a typical velocity is $R_{1} / t_{c}$ ) and the Suratman number $S=\sigma \rho_{1} R_{1} / \eta_{1}^{2}$. In our case, we will neglect gravitational effects because close densities prevent sedimentation in the time interval considered. Furthermore $S<<1$, due to the high viscosities used. Therefore we will look for a relation between 
$\eta_{1} R_{1} / \sigma t_{c}$ and the ratios $R_{1} / R_{2}$ and $\eta_{1} / \eta_{2}$. The system will be considered axisymmetric around the $z$-axis (figure 1), and this is verified experimentally.

In this particular paper, we will neglect viscoelastic effects, which are not important due to the particular choice of the fluids. Systems including viscoelasticity should therefore also include other dimensionless numbers such as the Weissenberg numbers.

\section{EXPERIMENTAL TECHNIQUE . -}

Two sets of polymers are used in the experiments. The first one is a series of polydimethylsiloxanes (PDMS, Rhône-Poulenc, 47VT series, three viscosities: 60 Pa.s, 100 Pa.s, 500 Pa.s at 20 C). The second polymer is polyisobutylene (PIB, BP chimie, D series, three viscosities: 58 Pa.s, 210 Pa.s, 705 Pa.s at $20^{\circ} \mathrm{C}$ ). Therefore nine different viscosity combinations may be considered, according to the inner and outer polymers chosen, PDMS or PIB. This allows a range of viscosity ratios of about two decades. The interfacial tension $\sigma$ is roughly $3 \mathrm{mN} / \mathrm{m}$, and is constant for the various systems. The relaxation times of these polymers are typically of the order of a few milliseconds, therefore elastic effects can be neglected, due to the longer times involved in the experiments.

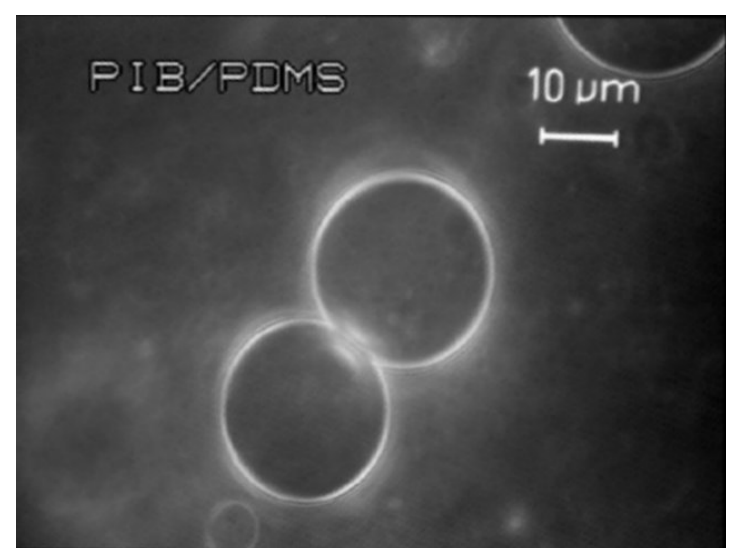

a) $t=0 \mathrm{~s}$

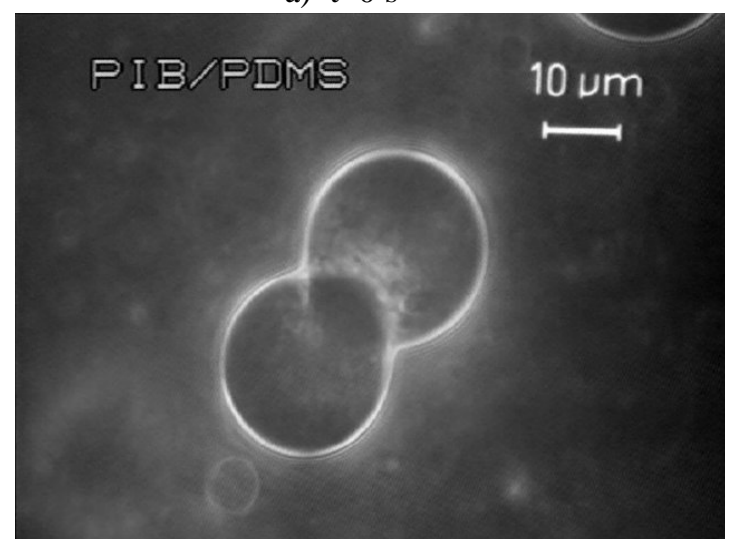

c) $\mathrm{t}=10.8 \mathrm{~s}$

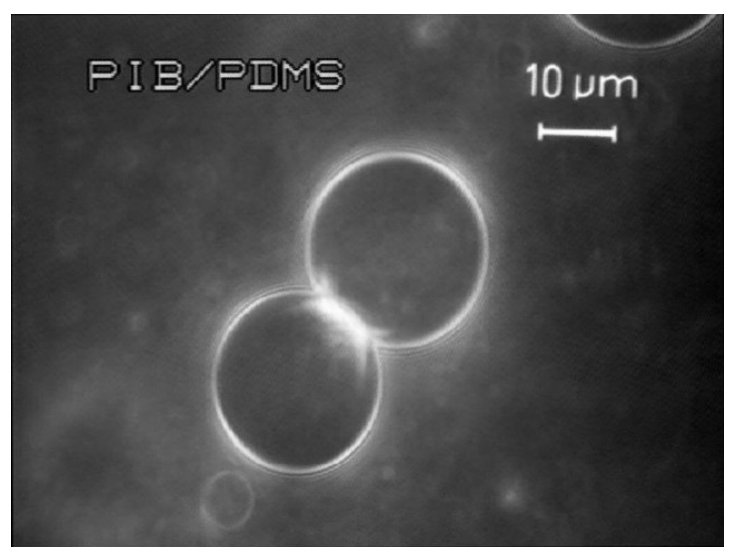

b) $\mathrm{t}=10 \mathrm{~s}$

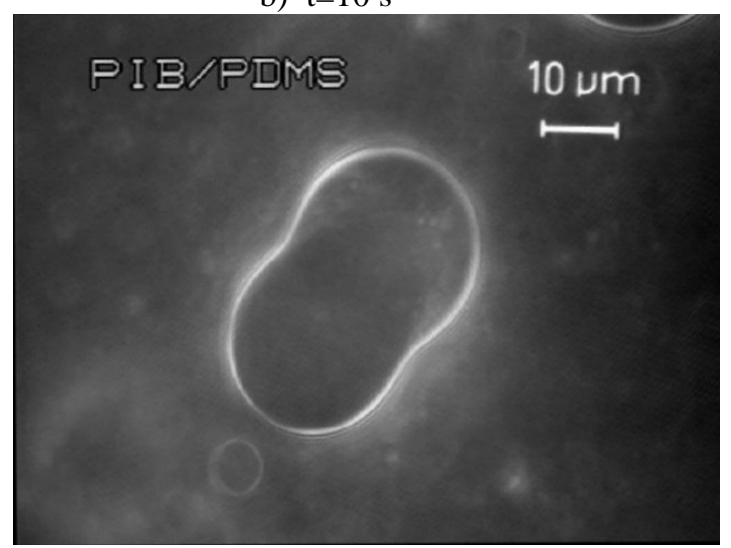

d) $\mathrm{t}=12.4 \mathrm{~s}$ 


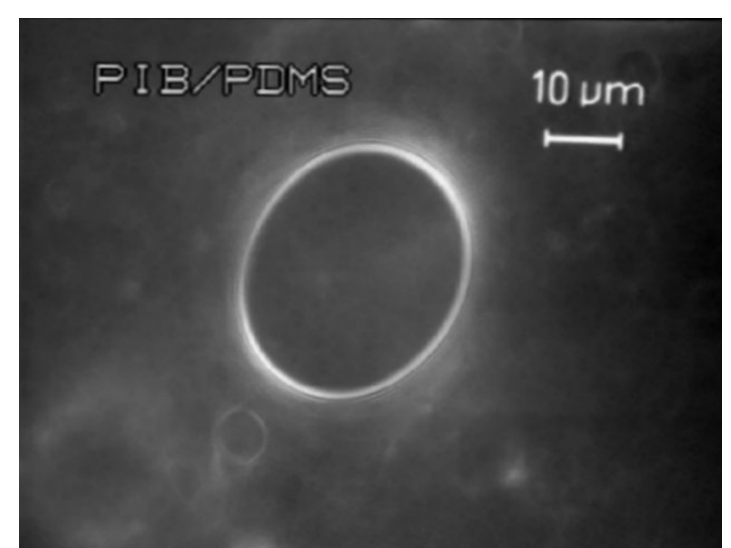

e) $\mathrm{t}=16.8 \mathrm{~s}$

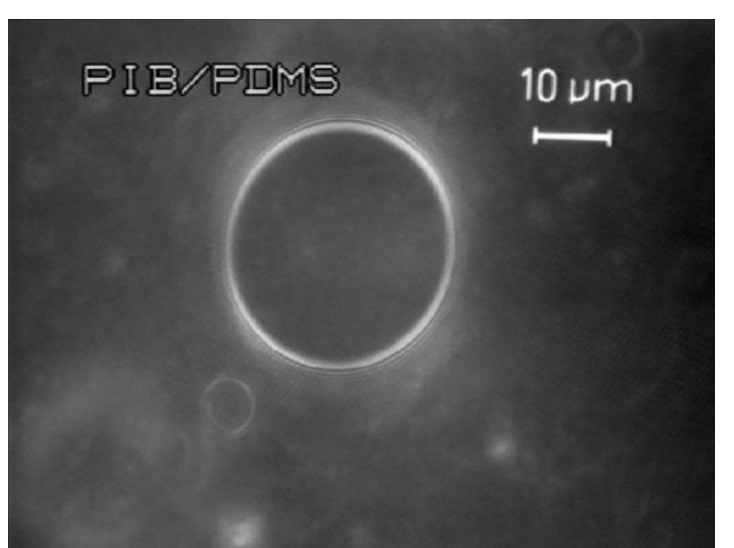

f) $t=21.6 \mathrm{~s}$

Fig. 2. - Collision of droplets of PIB (705 Pa.s) in PDMS (60 Pa.s)

Fig. 2. - Collision de gouttelettes de PIB (705 Pa.s) dans du PDMS (60 Pa.s)

The fluids are prepared by hand-mixing without using compatibilizers. The volume concentration of fluid 1 is about $5 \%$, so that a sufficient number of droplets is obtained and the droplets are not too close to each other. The resulting emulsion is placed between a glass plate and a micro cover glass, to be observed under a Leica microscope. Droplets are chosen in the middle of the glass plates, in order to avoid edge effects, so that we can consider that the motion is indeed three dimensional. The two droplets are located in the same plane so that both are in focus. This means that they should have about the same radius. They are not far from each other, so that the time to wait is not too long before they collide. Just before a hole is formed, the video camera is started and collision can be studied.

A typical experiment is depicted in the series of figures 2a-f. In this experiment, more viscous droplets (PIB, 705 Pa.s) are used in a matrix of less viscous fluid (PDMS, 60 Pa.s). We first start with two initial spherical droplets (figure 2a) almost touching. Then a hole is formed in about 10 seconds (figure 2b) and the droplets start to merge. After some short time (figure 2c), the droplets have already deformed under the action of interfacial tension. A little later (figure $2 \mathrm{~d}$ ), the newly-formed drop is showing a significant change. This drop is almost in its final equilibrium position after about 17 seconds (figure 2e), but more time is required for reaching equilibrium (figure $2 \mathrm{f}$ ).

To determine the characteristic time of the rapid stage of the collision, we choose to represent the graph $\mathrm{D}(\mathrm{t}) / \mathrm{D}_{0}$ versus time, sketched in figure $3 . \mathrm{D}(\mathrm{t})$ is the length of the final drop, and $\mathrm{D}_{0}=2\left(\mathrm{R}_{1}+\mathrm{R}_{2}\right)$ is the initial length if the drops touch.

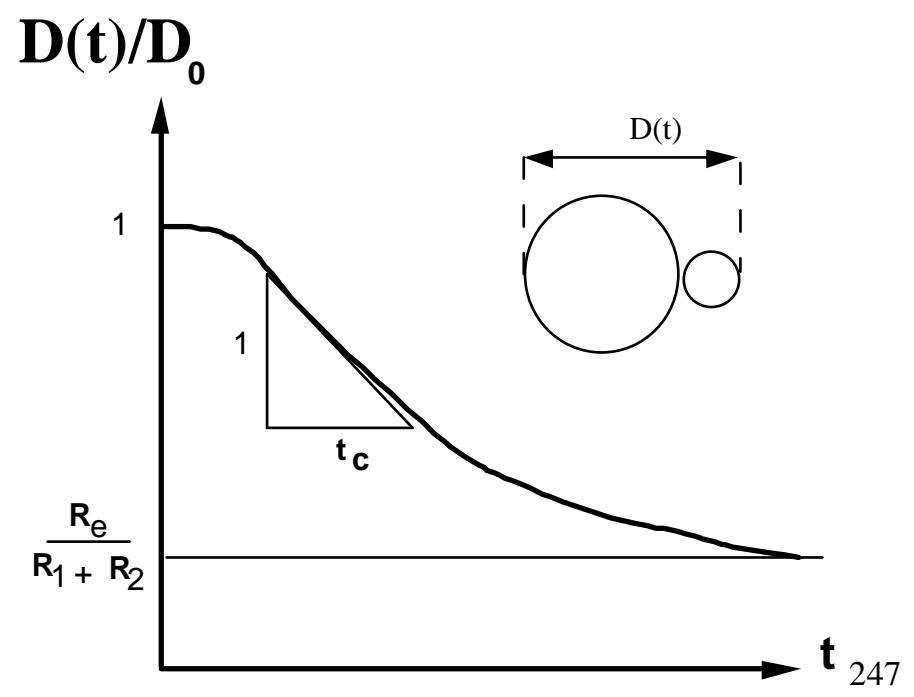

Fig. 3. - Determination of $\mathrm{t}_{\mathrm{c}}$ from the plot of $\mathrm{D}(\mathrm{t}) / \mathrm{D}_{0}$ vs. $\mathrm{t}$

Fig. 3. - Détermination de $t_{c}$ à partir de la courbe $D(t) / D_{0}$ vs. $t$ 
$\mathrm{D}(\mathrm{t}) / \mathrm{D}_{0}$ equals roughly 1 at time 0 , because of possible flattening effects. The interstitial fluid is finally removed until a hole is formed. Then a rapid decay is observed, where the slope $1 / t_{\mathrm{c}}$ is determined. This definition of $\mathrm{t}_{\mathrm{c}}$ has been chosen because it is difficult to determine exactly when the hole opens up. As a consequence, it seems very difficult to measure the hole radius, so that is why the length $D(t)$ is used instead. The final length of the drop is $2 R_{e}$ (at infinite time) where $R_{e}{ }^{3}=R_{1}{ }^{3}+R_{2}{ }^{3}$ from mass conservation. This final radius is obtained for infinite times, because of relaxational effects. The limiting value of $\mathrm{D}(\mathrm{t}) / \mathrm{D}_{0}$ at infinite time is $\mathrm{R}_{\mathrm{e}} /\left(\mathrm{R}_{1}+\mathrm{R}_{2}\right)$. This limiting value as a function of $\mathrm{R}_{1} / \mathrm{R}_{2}$ decreases from $1\left(R_{1}=0\right)$ to about $0.63\left(R_{1}=R_{2}\right)$, then increases again to $1\left(R_{2}=0\right)$. Therefore $t_{c}$, which is defined as the time required for a variation of $1\left(\right.$ of $\left.\mathrm{D}(\mathrm{t}) / \mathrm{D}_{0}\right)$ may appear a bit large because $\mathrm{D}(\mathrm{t}) / \mathrm{D}_{0}$ does not show variations larger than 0.37 . In figure 4 , the actual graph of $\mathrm{D}(\mathrm{t})$ deduced from figures 2 is shown.

We notice the plateau at short times corresponding to final drainage of fluid 2: the distance $\mathrm{D}(\mathrm{t})$ does not change much. A hole is opened at $t \sim 10 \mathrm{~s}$. The time $t_{\mathrm{C}}$ deduced from the slope is found to be $t_{\mathrm{C}} \sim 28 \mathrm{~s}$. This result corresponds to a viscosity ratio of $\eta_{1} / \eta_{2}=11.75$ ( $\eta_{1}=705$ Pa.s, $\eta_{2}=60$ Pa.s). Using the value of the interfacial tension of $3 \mathrm{mN} / \mathrm{m}$, and the radii $\mathrm{R}_{1}=12.9 \mu \mathrm{m}$ and $\mathrm{R}_{2}=10.9 \mu \mathrm{m}$, a corresponding reduced time $\sigma t_{C} / \eta_{1} R_{1}$ of about 9 is found (see figure 5 ).

The capillary number, which is the inverse of the reduced time, according to our definition, is found to be always smaller than one, as expected, because this flow is governed mainly by interfacial effects.

\section{RESULTS AND DISCUSSION . -}

The results corresponding to different viscosity ratios are depicted in figure 5. Sixteen different experiments were performed. A $\log -\log$ representation of the reduced time $\sigma t_{c} / \eta_{1} R_{1}$ vs. the viscosity ratio $\eta_{1} / \eta_{2}$ has been used.

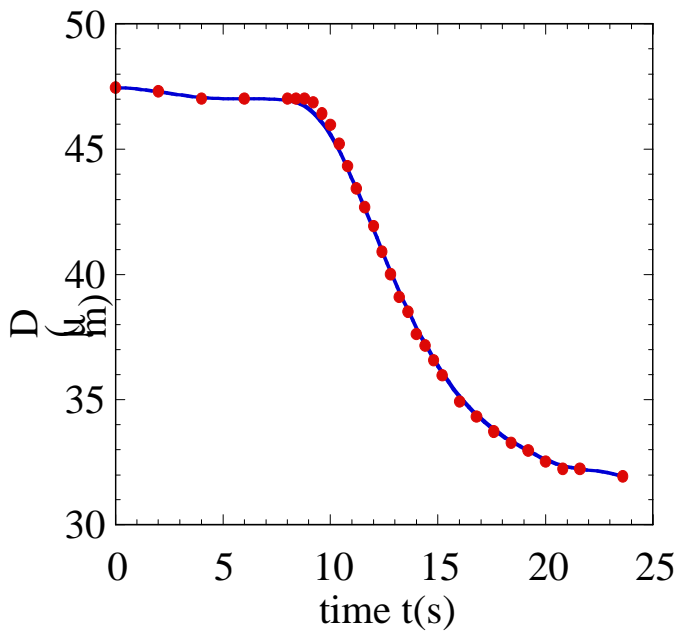

Fig. 4. - D(t) for droplets of PIB (705 Pa.s) in PDMS (60 Pa.s)

Fig. 4. - $D(t)$ pour des gouttelettes de PIB (705Pa.s) dans du PDMS (60 Pa.s)

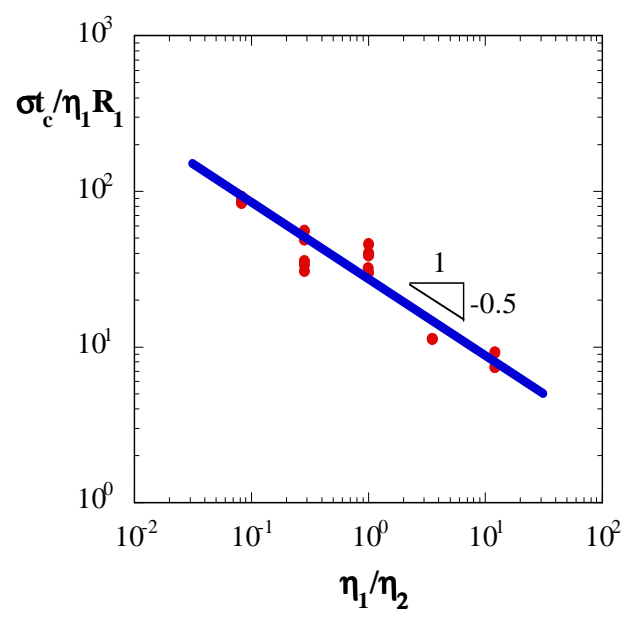

Fig. 5. - Reduced time $\sigma \mathrm{t}_{\mathrm{C}} / \eta_{1} \mathrm{R}_{1}$ versus $\eta_{1} / \eta_{2}$

Fig. 5. - Temps $\sigma_{C} / \eta_{1} R_{1}$ adimensionnel en fonction de $\eta_{1} / \eta_{2}$

In the experiments, the radius ratio of the drop does not change very much, a typical radius size for the drops is around $10 \mu \mathrm{m}$. Indeed, droplets have similar sizes, because the focus is easier to make in such a case. Therefore, we may assume that the only varying parameter is $\eta_{1} / \eta_{2}$, the ratio $R_{1} / R_{2}$ remaining a constant close to 1 . The slight scattering of the data is explained by differences in drop sizes. Nevertheless, the separate experiments (some repeated) were performed and the plot of $\sigma \mathrm{t}_{\mathrm{c}} / \eta_{1} \mathrm{R}_{1} \mathrm{vs}$. $\eta_{1} / \eta_{2}$ appears to show a typical slope of about -0.5 , over two decades. This means that $t_{c}$ varies like $\sqrt{\eta_{1} \eta_{2}}$, in other words the geometric mean of the viscosities of the two fluids. $t_{c}$ should increase when both viscosities increase, which is the case. Therefore it may be useful, in such a problem, to consider an 
equivalent capillary number based on the so-called effective viscosity $\eta_{e}=\sqrt{\eta_{1} \eta_{2}}$. At this point, no clear evidence of the importance of this viscosity can be found or modeled in the literature. The characteristic time $t_{c}$ varies like $t_{c} \sim \eta_{e} R_{1} / \sigma$. The influence of the other parameters is as expected. The larger the radius $\mathrm{R}_{1}$, the larger the time $\mathrm{t}_{\mathrm{c}}$ required to create the new surface. The larger the interfacial tension $\sigma$, the smaller the time ( $\sigma$ is the driving force).

This result is new and interesting because it shows the importance of an effective viscosity $\eta_{\mathrm{e}}$ responsible for the deformation of the interface, in a complex geometrical system where interfacial tension is the driving force.

\section{CONCLUSION. -}

It is often difficult to predict how the free surface of a two-phase system deforms when effects like interfacial tension and viscosities are present. This simple analysis of drop collision shows the role of an equivalent viscosity which may not have been guessed beforehand, in the case of a PDMS/PIB system. In addition, this original set-up may be very useful for the investigation of other effects such as interfacial tension, the influence of compatibilizers at the interface, and may finally be used for understanding coalescence in general, including the drainage, pinching, and collision phases. Finally, it could be generalized to viscoelastic systems.

Acknowledgments. The author is grateful to Pierre-Yves Longin for carrying out the video analysis concerning this work.

\section{REFERENCES}

[1] Chesters A.K., The modelling of coalescence processes in fluid-liquid dispersions: A review of current understanding. Trans I ChemE 69A (1991) 259-270.

[2] Kuczynski G.C., Self-diffusion in sintering of metallic particles. Transactions AIME 185 (1949) 169-178.

[3] Taylor G.I., The formation of emulsions in definable fields of flow. Proc. Royal Soc. 29 (1879) 501-523.

[4] Taylor G.I., The viscosity of a fluid containing small drops of another fluid, Proc. R. Soc. A138 (1932) 4148.

[5] Batchelor G.K., Green J.T., The hydrodynamic interaction of two small freely-moving spheres in a linear flow field. J. Fluid Mech. 56 (1972) 375-400.

[6] Barthès-Biesel D., Acrivos A., Deformation and burst of a liquid droplet freely suspended in a linear shear field. J. Fluid. Mech. 61 (1973) 1-21.

[7] Acrivos A., Lo T.S., Deformation and breakup of a single slender drop in an extensional flow. J. Fluid Mech. 86 (1978) 641-672.

[8] Adler P.M., Interaction of unequal spheres. I. Hydrodynamic interaction: colloidal forces. J. Colloid Interf. Sci. 84 (1981) 461-474.

[9] Grace H.P., Dispersion phenomena in high viscosity immiscible fluid systems and application of static mixers as dispersion devices in such systems. Chem. Eng. Commun. 14 (1982) 225-277.

[10] Yiantsios S.G., Davis R.H., On the buoyancy-driven motion of a drop towards a rigid surface or a deformable interface. J. Fluid Mech. 217 (1990) 547-573.

[11] Frenkel J., Viscous flow of crystalline bodies under the action of surface tension. J. Phys. USSR 9 (1949) 385-391.

[12] Hopper R.W., Plane-Stokes flow driven by capillarity on a free surface. J. Fluid Mech. 213 (1990) 349-375.

[13] Hopper R.W., Stokes flow of a cylinder and half-space driven by capillarity. J. Fluid Mech. 243 (1992) 171181.

[14] Mazur S., Plazek D.J., Viscoelastic effects in the coalescence of polymer particles. Prog. Organic Coat. 24 (1994) 225-236.

[15] Eggers J., Coalescence of spheres by surface diffusion. Phys. Rev. Letters 80 (1998) 2634-2637.

[16] Elmendorp J.J., van der Vegt A.K., A study on polymer blending microrheology: Part IV. The influence of coalescence on blend morphology origination. Polym. Eng. Sci. 26 (1986) 1332-1338.

[17] Janssen J.M.H., "Dynamics of liquid-liquid mixing". PhD thesis. Eindhoven University of Technology. Eindhoven. The Netherlands (1993).

[18] Fayt R., Jérôme R., Teyssié Ph., Molecular design of multicomponent polymer systems. I. Emulsifying effect of poly(hydrogenated butadiene-b-styrene) copolymers in LDPE/PS blends. J. Polym. Sci.: Polym. Lett. Ed. 19 (1981) 79-84. 
[19] Huneault M.A., Shi Z.H., Utracki L.A., Development of polymer blend morphology during compounding in a twin-screw extruder. Part IV: A new computational model with coalescence. Polym. Eng.Sci. 35 (1995) 115127.

[20] Fortelny I., Zivny A., Coalescence in molten quiescent polymer blends. Polymer 36 (1995) 4113-4118.

[21] Sundararaj U., Macosko C.W., Drop breakup and coalescence in polymer blends: The effects of concentration and compatibilization. Macromolecules 28 (1995) 2647-2657.

[22] Grizzuti N., Bifulco O., Effects of coalescence and breakup on the steady-state morphology of an immiscible polymer blend in shear flow. Rheol. Acta 36 (1997) 406-415.

[23] Vinckier I., Moldenaers P., Terracciano A.M., Grizzuti N., Droplet size evolution during coalescence in semiconcentrated model blends. AIChE J. 44 (1998) 951-958. 